\title{
A evolução do índice de envelhecimento no Brasil, nas suas regiões e unidades federativas no período de 1970 a 2010
}

\author{
Agingindex dedqporertin Brail, regions andfederdiveunitsfram1970 to2010
}

\section{Resumo}

Introdução: O Índice de Envelhecimento (IE) avalia o processo de ampliação do segmento idoso na população total em relação à variação relativa no grupo etário jovem, sendo obtido por meio da razão entre a população idosa e a população jovem. Este indicador permite observar a evolução do ritmo de envelhecimento da população, comparativamente entre áreas geográficas e grupos sociais e pode, assim, subsidiar a formulação, gestão e avaliação de políticas públicas nas áreas de saúde e de previdência social. Objetivo: Apresentar a evolução do IE no Brasil, regiões e unidades federativas, no período de 1970 a 2010. Métodos: Foi realizado um estudo descritivo, com dados obtidos dos Censos Demográficos e dos Indicadores Sociais do IBGE, do período de 1970 a 2010. Resultados: Em 2010, o IE do Brasil era de 44,8. Entre as regiões brasileiras, o Sul $(54,94)$ e Sudeste $(54,59)$ se equiparavam com o maior IE e o Norte $(21,84)$ apresentava o menor IE. As unidades federativas com maior IE eram Rio Grande do Sul $(65,47)$ e Rio de Janeiro $(61,45)$. Os menores índices pertenciam aos estados do Amapá $(15,45)$ e Roraima (16,57). No período de 1970 a 2010, observou-se aumento de $268 \%$ no IE do Brasil. Conclusão: Os resultados demonstram, indubitavelmente, que o Brasil se encontra em franco processo de envelhecimento da sua população, pois no período de 1970 a 2010, o IE teve um aumento progressivo, fato também observado nas suas diferentes regiões e unidades federativas.

\section{Abstract}

Introduction: The aging index (AI) assesses the process of the broadening of the elderly portion of the total population in relation to the relative variation in the young age group, where it is determined by the ratio of the elderly population to the young population. This indicator allows the observation of the evolution of the aging rhythm of the population, comparing geographic areas and social groups, and can thus help in the formulation, management and evaluation of public policies in the areas of health and social welfare.
Vera Elizabeth Closs' Carla Helena Augustin Schwanke ${ }^{1}$

\section{Palavras-chave:}

Envelhecimento da população. Envelhecimento Demográfico. Índices. Censo Demográfico. Transição demográfica. Brasil.

1 Instituto de Geriatria e Gerontologia. Pontifícia Universidade Católica do Rio Grande do Sul. Porto Alegre, RS, Brasil.

Key words: Aging Population. Census Demographic. Indexes. Demographic transition. Brazil. 
Objective: This study aimed to examine the evolution of AI in Brazil and its regions and federative units from 1970 to 2010. Methods: A descriptive study was conducted using data obtained from the Demographic Censuses and the Social Indicators of IBGE (Brazilian Institute of Geography and Statistics), for the period of 1970 to 2010. Results: In 2010, AI in Brazil was 44.8. Among the Brazilian regions, the South (54.94) and Southeast (54.59) had the highest AI; and the North (21.84), the lowest. The federative units with the highest AI were Rio Grande do Sul (65.47) and Rio de Janeiro (61.45). The lowest indices belonged to the states of Amapá (15.45) and Roraima (16.57). AI in Brazil increased 268\% during the study period. Conclusion: The results show that Brazil's population is truly in a process of aging, because from 1970 to 2010, AI showed a progressive increase, also observed in the different regions and federative units of the country.

\section{INTRODUÇÃO}

A população mundial encontra-se em um processo de reestruturação demográfica que se caracteriza pela redução das taxas de fecundidade, diminuição da mortalidade e consequente aumento da expectativa de vida. ${ }^{1} \mathrm{~A}$ transição demográfica vem acontecendo de forma heterogênea na população mundial e encontra-se em diferentes fases ao redor do mundo. ${ }^{2}$ Iniciouse na Europa, e o primeiro fenômeno observado foi a diminuição da fecundidade na Revolução Industrial, fato este anterior ao aparecimento da pílula anticoncepcional. Por outro lado, o aumento na expectativa de vida ocorreu de forma lenta, devido a melhores condições sociais e de saneamento, com o advento do uso de antibióticos e de vacinas. ${ }^{3}$

Muitos países, entre eles o Brasil, vêm passando por uma mudança em suas estruturas etárias, que se reflete em uma diminuição relativa na proporção de crianças e jovens e um aumento na proporção de adultos e idosos no conjunto da população. ${ }^{1}$

A população brasileira, até os anos 60 , revelava-se quase estável e sua distribuição etária caracterizava-se por uma quase constância. ${ }^{4}$ Tratava-se de uma população jovem, sendo que, no censo de $1970,42 \%$ da população tinham menos de 15 anos e 5\% tinham mais de 60 anos. ${ }^{5}$ Entre os anos 1940 e 1960, o Brasil experimentou um significativo declínio da mortalidade, mantendo a fecundidade em níveis bastante altos, o que gerou uma população jovem quase estável e com rápido crescimento. ${ }^{2}$ A esperança de vida ao nascer passou de aproximadamente 41 anos, na década de 30 , para 55,7 anos, na década de $60,{ }^{6}$ e a taxa de fecundidade total teria passado de 6,2 filhos por mulher, nos anos 40, para 5,8, em 1970.7

Ao final da década de 60, os níveis de fecundidade passaram a apresentar trajetória descendente, inicialmente nos grupos populacionais mais privilegiados e nos polos mais desenvolvidos, estendendo-se rapidamente às demais regiões. ${ }^{8,2} \mathrm{~A}$ participação relativa do grupo etário jovem declinou de 41,8\%, em 1950, para $28,6 \%$ em 2000, tendendo depois a estabilizar-se numericamente. ${ }^{9}$ Em contraposição, a população idosa (acima de 65 anos) mais do que duplicou sua importância relativa, passando de $2,4 \%$, em 1950 , para $5,4 \%$, em $2000{ }^{9}$

Assim, o grupo de idosos é, hoje, um contingente populacional expressivo em termos absolutos e de crescente importância relativa no conjunto da sociedade brasileira, daí decorrendo uma série de novas exigências e demandas em termos de políticas públicas de saúde e inserção ativa dos idosos na vida social. ${ }^{1}$ Este processo, denominado de envelhecimento populacional, vem sendo informado à sociedade, com base em pesquisas e estudos populacionais do Instituto Brasileiro de Geografia e Estatística (IBGE), ${ }^{1}$ por meio de indicadores sociais e demográficos, ferramentas necessárias para entender a dinâmica da sociedade em um determinado período de tempo. ${ }^{8,10}$ 
Dentre as várias alternativas para a observação do envelhecimento de uma determinada população, o Índice de Envelhecimento (IE) apresenta vantagens por ser analiticamente simples, apresentar alta sensibilidade às variações na distribuição etária, contabilizar os dois grupos etários que definem o processo de envelhecimento populacional e ser de fácil interpretação. ${ }^{11}$

O IE é definido como o número de pessoas de 60 e mais anos de idade, para cada 100 pessoas menores de 15 anos de idade, na população residente em determinado espaço geográfico, no ano considerado, ${ }^{12}$ e avalia o processo de ampliação do segmento idoso na população total em relação à variação relativa no grupo etário jovem. Quando há um aumento do grupo jovem maior do que o aumento dos idosos, o índice acusa o rejuvenescimento da população, a despeito de a ampliada participação dos idosos sugerir o envelhecimento da população. Por outro lado, se os dois grupos etários observarem variações de mesmo sentido e intensidade, o IE não varia, apresentando estabilidade no envelhecimento, apesar de a proporção de idosos indicar aumento ou redução do envelhecimento, conforme a direção da mudança. ${ }^{13}$

Nesse contexto, o objetivo do presente estudo é apresentar a evolução do Índice de Envelhecimento no Brasil, nas suas regiões e unidades federativas, no período de 1970 a 2010.

\section{METODOLOGIA}

Foi realizado um estudo descritivo, no qual foram utilizados dados obtidos dos Censos Demográficos ${ }^{5}$ e dos Indicadores Sociais do IBGE, ${ }^{1}$ do período de 1970 a 2010. Com base nestas fontes, foram pesquisadas as tabelas da população residente por grupos de idade, do Brasil, regiões geográficas e unidades da Federação. Os dados foram extraídos e agrupados de acordo com os grupos etários necessários para o cálculo do IE, ou seja, a população menor do que 15 anos de idade e a população de 60 anos e mais de idade. Estes resultados foram aplicados à equação:

$$
\text { Índice de Envelhecimento }=\frac{\mathrm{P}_{60}}{\mathrm{P}_{15}} \times 100
$$

Onde $\mathrm{P}_{60}$ é o número de pessoas residentes de 60 anos e mais de idade; $\mathrm{P}_{15}$ é o número de pessoas residentes com menos de 15 anos de idade. ${ }^{12}$

Para o cálculo do IE, são consideradas idosas as pessoas com mais de 65 anos em países desenvolvidos e aquelas com idade de 60 anos em países em desenvolvimento, como é o caso do Brasil. Estes parâmetros foram estipulados pelo Viena International Plan of Action on Ageing (United Nations World Assembly on Ageing, Resolução no. 39/125 de 1982) $)^{11}$ e, posteriormente, endossados pela Second World Assembly on Ageing, realizada em 2002 (Madrid International Plan of Action on Ageing). ${ }^{14}$ Assim, para manter a coerência com os demais indicadores e também para atender à Política Nacional do Idoso (Lei nº. 8842, de 4 de janeiro de 1994) ${ }^{15}$ e ao Estatuto do Idoso (Lei $\mathrm{n}^{\mathrm{o}} .10 .741$, de $1^{\mathrm{o}}$ de outubro de 2003), ${ }^{16}$ utilizou-se aqui o parâmetro de 60 anos ou mais.

Para a descrição dos dados, foram calculados, além do IE, o Delta percentual do IE $(\Delta \%$ IE) por meio da equação $\Delta \% \mathrm{IE}=100 \times$ [(IE atual $/$ IE anterior) -1]. Os cálculos e a construção dos gráficos foram realizados pelo programa Excel - Microsoft Office 2007, e os resultados foram apresentados em gráficos e tabelas.

\section{RESULTADOS}

O IE será apresentado em três contextos: no Brasil, nas suas diferentes Regiões e Unidades Federativas.

O IE no Brasil, em 2010, era de 44,8. A figura 1 apresenta a evolução deste indicador desde a década de 70 . 


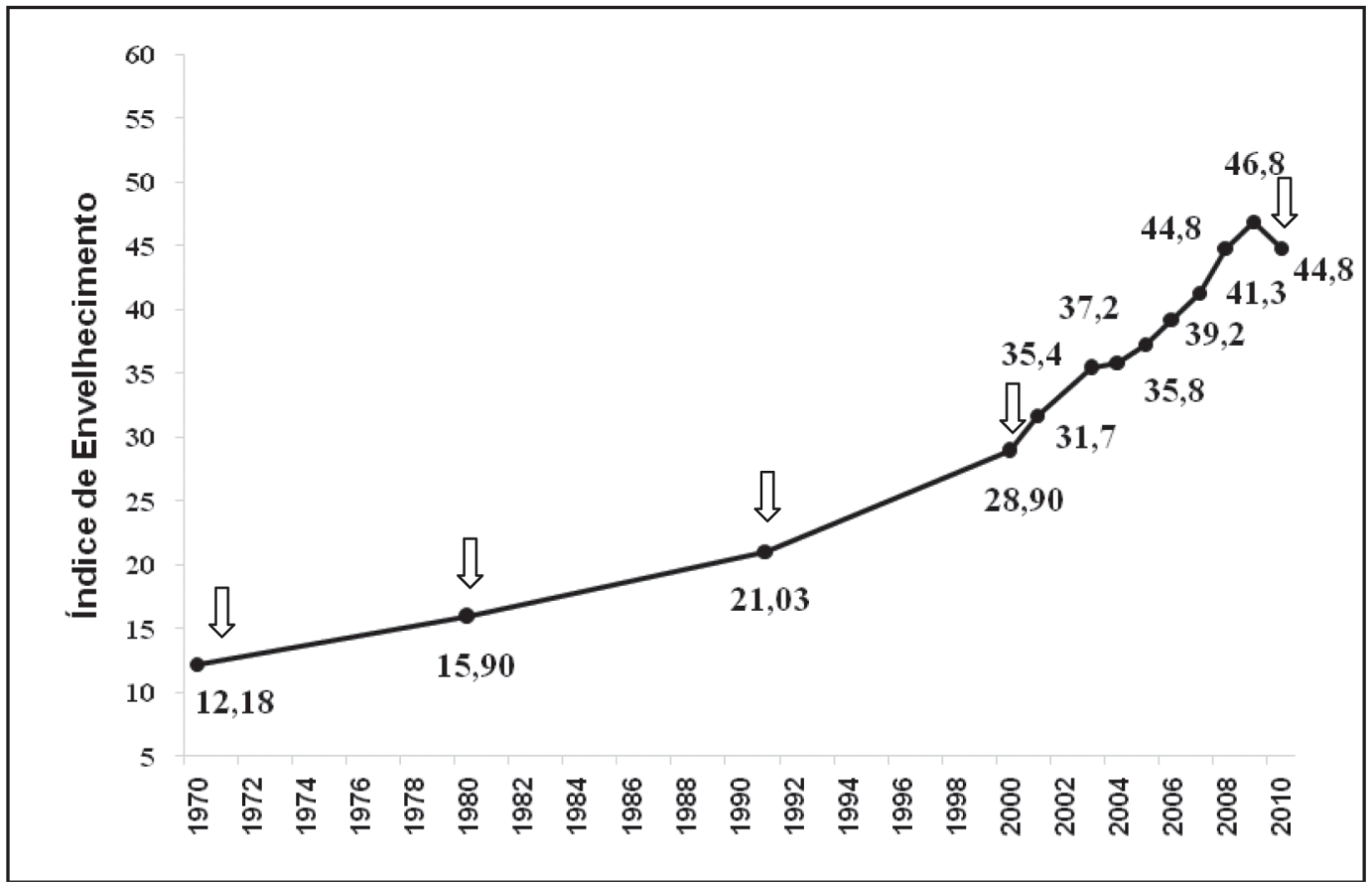

Figura 1. Índice de Envelhecimento do Brasil. 1970-2010

Fonte: Elaborada pelas autoras, sendo que o Índice de Envelhecimento foi obtido com base em cálculos disponibilizados nos Censos Demográficos de 1970, 1980, 1991, 2000 e 2010; e Síntese de Indicadores Sociais de 2001-2009, do Instituto Brasileiro de Geografia e Estatística (IBGE). ${ }^{1,5}$

No período entre 1970 e 2010, pode-se observar que o IE brasileiro apresentou aumento progressivo: de 1970 a 1980, teve variação de 30,54\%; de 1980 a 1991, de 32,26\%, de 1991 a 2000 variou $37,42 \%$ e de 2000 a $2010,55,11 \%$.
Observa-se um ponto de partida distinto do IE nas regiões, bem como uma evolução diferenciada do mesmo em virtude das diferenças regionais no envelhecimento (figura 2). 


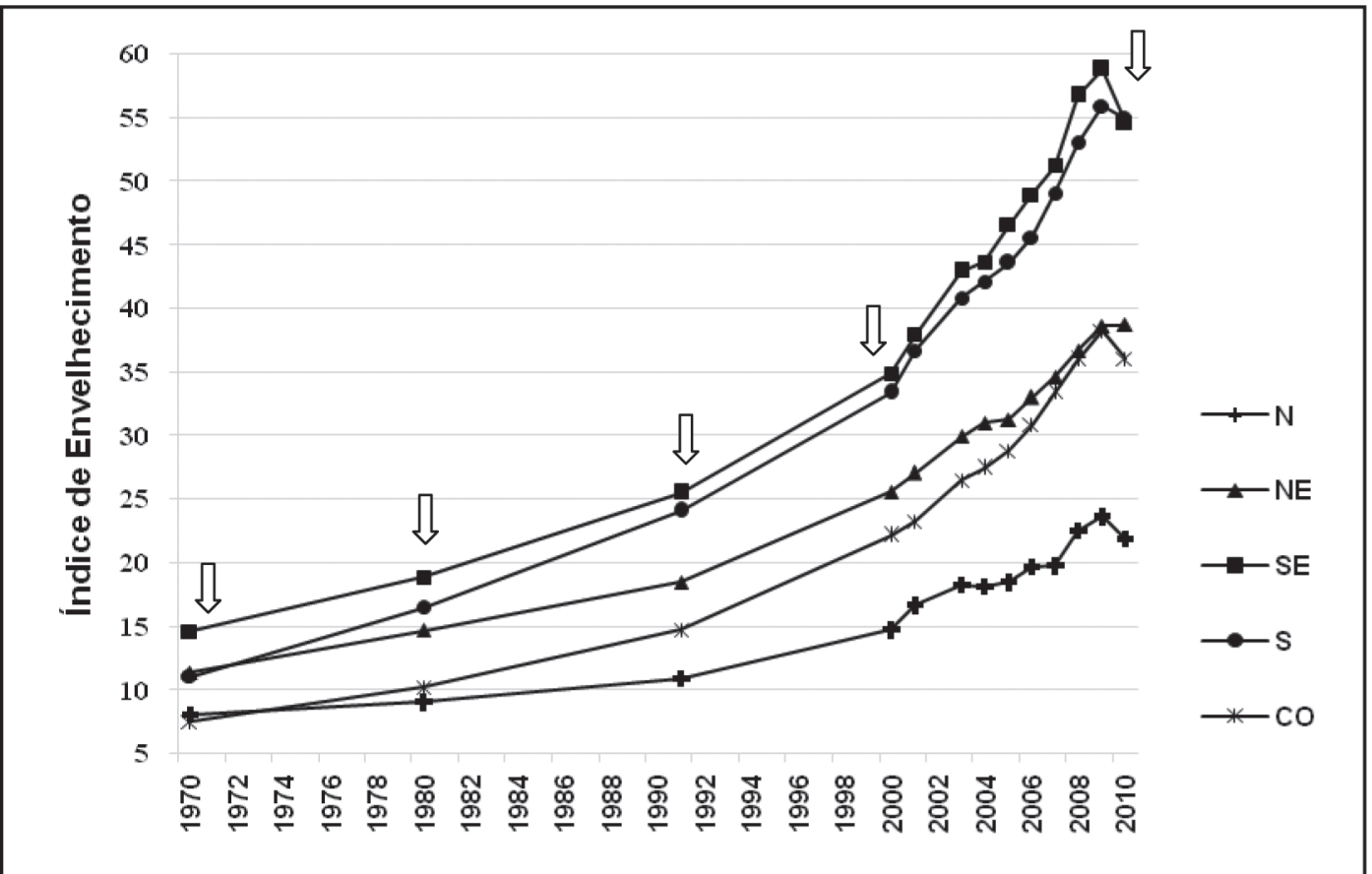

Figura 2. Índice de Envelhecimento das Regiões do Brasil. 1970-2010

Fonte: Elaborada pelas autoras, sendo que o Índice de Envelhecimento foi obtido com base em cálculos disponibilizados nos Censos Demográficos de 1970, 1980, 1991, 2000 e 2010; e Síntese de Indicadores Sociais de 2001-2009, do Instituto Brasileiro de Geografia e Estatística (IBGE). ${ }^{1,5}$

Nos anos 70, o IE vigente na Região Sudeste $(14,56)$ era quase o dobro daquele encontrado no Centro-Oeste do país $(7,45)$ e no Norte $(8,04)$. As regiões Sul $(11,03)$ e Nordeste $(11,33)$ apresentavam IEs semelhantes.

Mesmo com uma trajetória mais lenta das duas regiões brasileiras mais populosas (Sudeste e Nordeste), nos movimentos de evolução do IE, em 2000 persistiam as diferenças regionais. No censo daquele ano, mesmo com alguma atenuação em relação ao momento inicial do processo, encontrávamos um IE da população do Sul $(33,33)$ e do Sudeste $(34,83)$ elevado em mais de 50\% em relação ao Centro-Oeste.
No último censo, de 2010, as regiões Sul $(54,94)$ e Sudeste $(54,59)$ se equiparavam com o maior IE entre as regiões e a Região Norte $(21,84)$ apresentava o menor IE.

Norte, Nordeste e Sudeste são as regiões que apresentaram um processo de envelhecimento populacional mais lento no período de 1970 a 2010, (171\%, 241\% e 274\%, respectivamente), em contrapartida à Região Sul, que teve o maior percentual de aumento do índice neste intervalo (398\%).

Os dados relativos ao IE das Unidades Federativas são apresentados na tabela 1. 
Tabela 1. Índice de envelhecimento das unidades da federação de acordo com os Censos Demográficos de 1970-2000, Síntese de Indicadores Sociais de 2001-2009 e Censo Demográfico de 2010.

\begin{tabular}{|c|c|c|c|c|c|c|c|c|c|c|c|c|c|}
\hline \multirow{3}{*}{$\begin{array}{l}\text { Unidades da } \\
\text { Federação }\end{array}$} & \multicolumn{13}{|c|}{ ÍNDICE DE ENVELHECIMENTO } \\
\hline & \multicolumn{4}{|c|}{ Censo } & \multicolumn{8}{|c|}{ Síntese de Indicadores Sociais } & \multirow{2}{*}{$\begin{array}{r}\text { Censo } \\
2010\end{array}$} \\
\hline & 1970 & 1980 & 1991 & 2000 & 2001 & 2003 & 2004 & 2005 & 2006 & 2007 & 2008 & 2009 & \\
\hline Acre & 5,76 & 8,28 & 10,83 & 13,97 & 15,67 & 19,03 & 15,35 & 15,9 & 17,74 & 15,83 & 19,45 & 20,08 & 18,98 \\
\hline Alagoas & 11,13 & 13,98 & 15,93 & 20,46 & 24,38 & 25,1 & 27,51 & 26,92 & 29,47 & 32,54 & 30,82 & 34,97 & 30,4 \\
\hline Amapá & 6,09 & 8,23 & 8,64 & 10,32 & 23,67 & 16,37 & 13,2 & 14,13 & 14,22 & 14,33 & 14,88 & 19,2 & 15,45 \\
\hline Amazonas & 6,87 & 8,01 & 9,65 & 12,51 & 13,16 & 14,26 & 14,58 & 15,07 & 17,38 & 16,19 & 19,05 & 20,77 & 18,19 \\
\hline Bahia & 11,01 & 13,87 & 17,34 & 25,76 & 28,36 & 30,24 & 31,94 & 31,81 & 34,02 & 35,84 & 38,61 & 40,3 & 40,42 \\
\hline Ceará & 11,68 & 14,85 & 19,93 & 26,45 & 27,73 & 30,86 & 31,51 & 32,92 & 34,16 & 37,08 & 40,42 & 38,86 & 41,56 \\
\hline Distrito Federal & 5,08 & 7,35 & 11,84 & 18,78 & 17,01 & 23,81 & 22,44 & 23,96 & 25,4 & 29,31 & 31,8 & 33,67 & 32,48 \\
\hline Espírito Santo & 10,2 & 14,99 & 19,3 & 28,14 & 26,23 & 33,93 & 34,37 & 32,02 & 35,68 & 39,28 & 45,52 & 44,64 & 44,94 \\
\hline Fernando de Noronha & 2,24 & 1,52 & 0 & 0 & 0 & 0 & 0 & 0 & 0 & 0 & 0 & 0 & 0 \\
\hline Goiás & 7,71 & 10,88 & 16,66 & 24,42 & 25,36 & 28,53 & 31,57 & 31,71 & 33,7 & 36,18 & 39,19 & 40,12 & 38,96 \\
\hline Guanabara & 25,11 & $\diamond$ & $\diamond$ & $\diamond$ & $\diamond$ & $\diamond$ & $\diamond$ & $\diamond$ & $\diamond$ & $\diamond$ & $\diamond$ & $\diamond$ & $\diamond$ \\
\hline Maranhão & 8,96 & 11,75 & 13,73 & 19,23 & 20,03 & 24,9 & 23,52 & 23,55 & 24,45 & 26,42 & 26,65 & 29,67 & 27,96 \\
\hline Mato Grosso & 7,71 & 9,17 & 11,52 & 18,13 & 19 & 19,75 & 22,41 & 23,73 & 28,25 & 26,63 & 31,96 & 36,37 & 30,74 \\
\hline Mato Grosso do Sul & 0 & 11,13 & 16,49 & 24,69 & 29,54 & 33,02 & 28,92 & 33 & 32,53 & 39,65 & 37,1 & 40,21 & 39,11 \\
\hline Minas Gerais & 11,19 & 16,02 & 22,28 & 31,97 & 35,07 & 39,07 & 39,22 & 41,99 & 44,07 & 45,47 & 50,56 & 53,57 & 52,58 \\
\hline Pará & 9,1 & 9,97 & 11,49 & 15,49 & 16,83 & 19,56 & 19,29 & 19,03 & 19,99 & 22,16 & 23,62 & 23,64 & 22,73 \\
\hline Paraíba & 13,42 & 18,34 & 23,87 & 32,33 & 33,45 & 37,46 & 34,51 & 35,44 & 39,77 & 40,58 & 44,42 & 43,29 & 47,37 \\
\hline Paraná & 8,29 & 12,51 & 20,52 & 29,44 & 32,12 & 35,37 & 37,4 & 38,7 & 39,33 & 42,54 & 46,54 & 50,27 & 48,96 \\
\hline Pernambuco & 11,92 & 15,98 & 21,26 & 28,61 & 27,44 & 30,62 & 32,16 & 31,67 & 33,72 & 35,89 & 36,82 & 41,28 & 41,56 \\
\hline Piauí & 9,31 & 12,4 & 16,17 & 24,83 & 30,24 & 32,51 & 36,96 & 34,16 & 35,01 & 39,29 & 40,88 & 42,07 & 39,98 \\
\hline Rio de Janeiro & 12,89 & 23,04 & 32,54 & 42,59 & 47,65 & 57 & 59,23 & 61,65 & 67,72 & 67,39 & 73,32 & 75,07 & 61,45 \\
\hline Rio Grande do Norte & 13,11 & 17,85 & 22,08 & 28,57 & 29,07 & 31,7 & 34,32 & 34,82 & 38,07 & 33,46 & 39,81 & 42,46 & 43,62 \\
\hline Rio Grande do Sul & 14,82 & 22,26 & 29,68 & 40,12 & 42,37 & 49,66 & 49,88 & 52,07 & 53,3 & 57,62 & 61,39 & 64,55 & 65,47 \\
\hline Rondônia & 5,49 & 6,21 & 9,36 & 15,09 & 18,59 & 18,52 & 19,84 & 20,2 & 21,77 & 22,55 & 24,9 & 26,92 & 26,56 \\
\hline Roraima & 5,96 & 8,23 & 8,51 & 10,57 & 15,57 & 10,15 & 12,36 & 14,03 & 12,38 & 15,2 & 14,59 & 14,24 & 16,57 \\
\hline Santa Catarina & 10,1 & 14,45 & 20,41 & 28,49 & 34,46 & 34,76 & 36,51 & 37,41 & 42,96 & 45,89 & 50,48 & 51,05 & 48,22 \\
\hline São Paulo & 16,01 & 19,12 & 25,11 & 34,05 & 36,88 & 40,78 & 41,27 & 44,86 & 46,26 & 49,58 & 55,02 & 57 & 53,85 \\
\hline Sergipe & 12,57 & 15,3 & 17,31 & 21,97 & 22,2 & 25,3 & 28,06 & 34,85 & 32,54 & 27,4 & 28,92 & 31,71 & 33,43 \\
\hline Tocantins & * & $*$ & 13,52 & 19,14 & 22,66 & 23,41 & 25,46 & 27,36 & 28,27 & 28,85 & 32,23 & 35,81 & 29,54 \\
\hline
\end{tabular}

*Estado criado em 1988. $\diamond$ Estado fundido com o estado do Rio de Janeiro em 1975.

Fonte: Elaborada pelas autoras, sendo que o Índice de Envelhecimento foi obtido com base em cálculos disponibilizados nos Censos Demográficos e Síntese de Indicadores Sociais do Instituto Brasileiro de Geografia e Estatística (IBGE) ${ }^{1,5}$ 
No ano de 1970, os dados revelavam que o Estado da Guanabara, fundido com o Estado do Rio de Janeiro em 1975, apresentava o IE mais elevado (25,1), seguido de São Paulo (16,01). O Distrito Federal $(5,08)$ mostrava o menor IE, acompanhado de cinco estados da região amazônica [Rondônia (5,49), Acre $(5,76)$, Roraima $(5,96)$, Amapá $(6,09)$ e Amazonas $(6,87)]$.

No Censo Demográfico divulgado em abril de 2011, ${ }^{5} 19$ estados apresentaram IE inferior ao global do Brasil, que foi de 44,83, e oito estados tiveram índice superior (Rio Grande do Sul, Rio de Janeiro, São Paulo, Minas Gerais, Paraná, Santa Catarina, Paraíba e Espírito Santo). Quatro estados do Norte apresentaram índices entre $22 \mathrm{e}$ 29 pontos abaixo do índice global e o Rio Grande do Sul apresentou o maior índice (66,47), 20,64 pontos acima do geral do país, ${ }^{5}$ posição ocupada pelo Rio de Janeiro $(75,07)$ em 2009 , de acordo com a Síntese de Indicadores Sociais.

No período analisado, ou seja, de 1970 a 2010, os estados que tiveram menor incremento no seu IE foram Pará (149\%) e Amapá (153\%), e aqueles que resultaram em um delta percentual maior foram Distrito Federal (539\%) e Paraná (490\%). ${ }^{1,5}$

\section{DISCUSSÃO}

Valores elevados do IE indicam que a transição demográfica encontra-se em estágio avançado e, por meio deste índice, é possível acompanhar a evolução do ritmo de envelhecimento da população, comparativamente entre áreas geográficas e grupos sociais. Sua análise permite avaliar tendências da dinâmica demográfica e, assim, subsidiar a formulação, gestão e avaliação de políticas públicas em diversas áreas, como da saúde e da previdência social. ${ }^{12}$

Dados do Censo Demográfico brasileiro de $2010,{ }^{5}$ divulgados em abril de 2011, apresentaram o balanço entre a população idosa e os jovens menores de 15 anos, resultando em um IE de 44,8. Este resultado representa um aumento de $268 \%$ em relação ao Censo de 1970, demonstrando que a população do Brasil se encontra em franco processo de envelhecimento.

No período de 2000 a 2050, esta variação, segundo estimativas das Nações Unidas, ${ }^{17}$ será de $338 \%$, demonstrando que o envelhecimento da população brasileira é um processo irreversível e evidenciando a participação de uma população idosa, cada vez mais presente na sociedade.

Assim como outros indicadores demográficos, o IE vem apontando para mudanças que indicam que o país caminha para um perfil demográfico cada vez mais envelhecido. Se mantidas as hipóteses de queda futura dos níveis da fecundidade no país, haverá, em 2050, segundo as Nações Unidas, 118 idosos para cada 100 crianças e adolescentes. ${ }^{17}$

No Brasil, de acordo com Moreira, ${ }^{13}$ o declínio da mortalidade e a diminuição das taxas de fecundidade não ocorreram simultaneamente e com a mesma intensidade entre as regiões brasileiras. Dados analisados pela RIPSA, ${ }^{12}$ relativos aos anos de 1992, 1996 e 1999, já mostravam as regiões Sudeste e Sul mais adiantadas no processo de transição demográfica, apresentando os maiores IE. Os valores mais baixos nas regiões Norte e CentroOeste refletiam a influência das migrações, atraindo pessoas em idades jovens, muitas vezes acompanhadas de seus filhos. Os resultados do Censo de 2010 confirmaram a manutenção destas posições, anteriormente consquistadas. ${ }^{5}$

Os estados brasileiros acompanham, também, o processo de reestruturação, apresentando uma nova configuração de padrão demográfico. $\mathrm{O}$ resultado deste movimento vem sendo mais representativo nos estados do Rio de Janeiro e Rio Grande do Sul, como já observado por Moreira em 1998. ${ }^{18}$ Desde 1980, o estado do Rio de Janeiro vem apresentando IE superior ao Rio Grande do Sul e somente no Censo de 2010 esta posição se inverteu, passando o Rio Grande do Sul a ocupar a primeira posição entre os estados brasileiros, e o Rio de Janeiro, a segunda. 
O IE é útil na avaliação das diferenças no nível de envelhecimento da população dentro do país. Pode haver diferenças significativas entre estados e, também, entre zonas urbanas e rurais ${ }^{19}$ e em grandes nações como o Brasil, podem ocorrer diferenças mais amplas ainda. De acordo com dados do Censo de $2010,{ }^{5}$ o IE do Brasil variou para menos 22 a 29 pontos em estados da Região Norte do país e para mais 20 pontos no Rio Grande do Sul. O IE deverá se tornar mais homogêneo à medida que os valores relativos aos baixos níveis de fecundidade forem se aproximando entre as regiões. ${ }^{12}$

Shryock \& Siegel $^{20}$ definem o IE como o melhor indicador do envelhecimento demográfico e consideram um valor menor 15 como indicativo de uma população jovem; entre 15 e 30, uma população em nível intermediário; e acima de 30, uma população idosa. De acordo com esta classificação, a população do Brasil, de suas regiões (exceto a Norte), bem como de 19 estados brasileiros, pode ser considerada idosa.

No conjunto do país, o contingente de pessoas de mais de 60 anos é de cerca de 20 milhões. ${ }^{5}$ Analisando-se o contexto internacional, este número supera a população de idosos de vários países europeus, entre os quais França, Inglaterra e Itália (entre 14 e 16 milhões), de acordo com as estimativas das Nações Unidas.?

O Brasil apresenta um processo de envelhecimento mais veloz, contrastando com o observado nos países mais envelhecidos, nos quais a transição se iniciou bem antes e se deu em um lapso de tempo mais estendido.' Os dados colocam o Brasil entre os 35 países mais populosos do mundo, com o quarto mais intenso processo de envelhecimento, após a República da Coreia, Tailândia e Japão. Há projeções de que, no período de um século, o Brasil multiplicará em 12 vezes seu IE; a República da Coreia, 21 vezes; a Tailândia, 19; e o Japão, em torno de 16 vezes. ${ }^{9}$
Em 2000, o Brasil encontrava-se na $77^{a}$ posição no contexto mundial, com IE igual a 27,1, idêntico ao da América do Sul. Segundo projeções das Nações Unidas, ${ }^{17}$ em 2050, o IE brasileiro (118) ainda será menor que o da Europa Ocidental (254) e do Leste Asiático (190) e o país deverá encontrar-se na $81^{a}$ posição.

Comparando o Brasil aos países da América Latina e Caribe, os dados apontam para um processo de envelhecimento semelhante. No período de 2000 a 2050, o IE deverá ter um aumento relativo menor, de $338 \%$ contra $345 \%$, da América Latina. ${ }^{17}$

A análise do envelhecimento populacional de forma global revela que, em 2000, o IE mundial era de 33,4, e a estimativa para 2050 é de que seja de 100,5, demonstrando ser evidente o fenômeno do envelhecimento populacional. ${ }^{17}$ Porém, entre os países, este processo também não acontece de forma homogênea, sendo o IE maior nas regiões mais desenvolvidas, mas com crescimento maior previsto para as regiões menos desenvolvidas. ${ }^{17}$

Os registros demográficos assinalam a existência de mundos distintos: de um lado, os países menos desenvolvidos, com elevado número de idosos, mas com peso relativamente pequeno, de outro, os países mais desenvolvidos, onde o tamanho absoluto da população idosa é menor, mas sua participação relativa no total da população é maior. ${ }^{9}$

Em 2002, a Divisão Populacional das Nações Unidas ${ }^{17}$ preparou um relatório para a Second World Assembly on Ageing, com dados de 187 países. O documento fornece uma descrição das tendências globais de envelhecimento populacional e inclui, entre uma série de indicadores, o IE. Tratase do único documento que sintetiza todas as informações sobre o IE de diversos países (187) identificado na revisão bibliográfica realizada para elaboração da discussão do presente estudo. Sua relevância também está amparada na credibilidade do órgão que a produziu. 
Tabela 2. Índice de Envelhecimento no mundo, anos de 1950-2050, ordenados de acordo com os dados do ano 2000.

\begin{tabular}{|c|c|c|c|c|c|c|}
\hline \multicolumn{7}{|c|}{ ÍNDICE DE ENVELHECIMENTO } \\
\hline Posição & País & 1950 & 1975 & 2000 & 2025 & 2050 \\
\hline 1 & Itália & 46,5 & 71,8 & 168,5 & 311 & 369,2 \\
\hline 2 & Japão & 21,7 & 48,1 & 157,9 & 290 & 338,2 \\
\hline 3 & Grécia & 34,8 & 72,8 & 155,4 & 261,4 & 309,9 \\
\hline 4 & Alemanha & 63 & 94,9 & 149,7 & 271,9 & 307,5 \\
\hline 5 & Espanha & 40,4 & 52,1 & 147,9 & 283,1 & 386,4 \\
\hline 6 & Bulgária & 38 & 73,2 & 137,6 & 226,4 & 279,1 \\
\hline 7 & Bélgica & 76,4 & 86,2 & 128 & 223 & 250,3 \\
\hline 8 & Suíça & 59,6 & 77,9 & 127,8 & 287,8 & 310,4 \\
\hline 9 & Portugal & 35,5 & 51,4 & 124,9 & 199,7 & 248,1 \\
\hline 10 & Áustria & 67,7 & 87,6 & 124,8 & 282,4 & 355 \\
\hline 11 & Suécia & 63,7 & 101,6 & 123 & 238,2 & 270,1 \\
\hline 12 & Eslovênia & 38,3 & 64,7 & 120,8 & 278,3 & 341,7 \\
\hline 13 & Letônia & 61,6 & 84,2 & 120 & 209,7 & 249,8 \\
\hline 14 & Hungria & 45,1 & 90 & 116,5 & 205,4 & 251,3 \\
\hline 15 & Ucrânia & 40,2 & 68,6 & 115,2 & 206 & 294,3 \\
\hline 16 & Estônia & 57,9 & 78,6 & 114,1 & 189,8 & 230,4 \\
\hline 17 & Ilhas do Canal & 80,5 & 100,9 & 113 & 240,6 & 266,9 \\
\hline 18 & República Tcheca & 51,7 & 82,3 & 111,8 & 243 & 296,1 \\
\hline 19 & Croácia & 42,3 & 72,1 & 111,8 & 164,7 & 189 \\
\hline 20 & Finlândia & 33,9 & 70,5 & 110,5 & 218,7 & 228,7 \\
\hline 21 & França & 71,5 & 76,4 & 109,6 & 173,6 & 204,3 \\
\hline 22 & Dinamarca & 50,9 & 82,8 & 109,5 & 201,6 & 209,9 \\
\hline 23 & Reino Unido & 69,5 & 84,1 & 108,7 & 197 & 226,7 \\
\hline 24 & Luxemburgo & 72,9 & 86,2 & 103,8 & 139,5 & 142,6 \\
\hline 25 & Rússia & 31,8 & 58,4 & 103,1 & 197,3 & 274,9 \\
\hline 26 & Romênia & 30,6 & 56,5 & 103,1 & 156,9 & 215,4 \\
\hline 27 & Bielo-Rússia & 47,6 & 55,7 & 101,1 & 179,3 & 244,7 \\
\hline 28 & Holanda & 39,1 & 59,7 & 99,9 & 204,9 & 223,3 \\
\hline 29 & Noruega & 56,8 & 80,4 & 99 & 180,6 & 201 \\
\hline 30 & Lituânia & 48,6 & 59,4 & 95,4 & 200,2 & 255,3 \\
\hline 31 & Geórgia & 55,5 & 43,8 & 91,5 & 177 & 248,8 \\
\hline 32 & Sérvia e Montenegro & 38,11 & 52,5 & 91,4 & 157,1 & 214,1 \\
\hline 33 & China Hong Kong & 12,2 & 29,1 & 87,8 & 207,2 & 255,8 \\
\hline
\end{tabular}




\begin{tabular}{|c|c|c|c|c|c|c|}
\hline Posição & País & 1950 & 1975 & 2000 & 2025 & 2050 \\
\hline 34 & Canadá & 38,2 & 47,2 & 87,3 & 173,7 & 186,6 \\
\hline 35 & Polônia & 28 & 57,3 & 86,5 & 179,6 & 226,9 \\
\hline 36 & Malta & 26,6 & 53,1 & 84,3 & 172,5 & 220 \\
\hline 37 & Austrália & 47 & 46,4 & 79,6 & 140,5 & 159,6 \\
\hline 38 & Eslováquia & 34,4 & 52,9 & 79 & 179,1 & 279,3 \\
\hline 39 & Bósnia e Herzegovina & 16,1 & 26,3 & 78,8 & 208,6 & 291,3 \\
\hline 40 & Estados Unidos & 46,3 & 58,8 & 74,4 & 133,8 & 144,9 \\
\hline 41 & Irlanda & 51,2 & 49,6 & 70,6 & 104,5 & 144,7 \\
\hline 42 & Uruguai & 42,3 & 51 & 69,2 & 93,7 & 129,8 \\
\hline 43 & Chipre & 26,4 & 53,7 & 67,8 & 129,1 & 179,5 \\
\hline 44 & Nova Zelândia & 45 & 42,4 & 67,8 & 146,5 & 171,6 \\
\hline 45 & Martinica & 20,5 & 23,2 & 66,6 & 140,3 & 207,2 \\
\hline 46 & Islândia & 34,1 & 42,3 & 64,9 & 132,2 & 170 \\
\hline 47 & Barbados & 25,7 & 43,3 & 64,7 & 162,2 & 235,2 \\
\hline 48 & Cuba & 20,4 & 26,4 & 64,3 & 156,8 & 220,5 \\
\hline 49 & Macedônia & 31,6 & 30 & 63,6 & 155,8 & 238,6 \\
\hline 50 & Porto Rico & 14,2 & 27,5 & 59,9 & 108,2 & 164,4 \\
\hline 51 & Moldávia & 40 & 37,4 & 59,1 & 129,4 & 212,4 \\
\hline 52 & Armênia & 37 & 24,3 & 55,4 & 171,8 & 323 \\
\hline 53 & Coreia do Sul & 13,1 & 15,4 & 52,7 & 150,7 & 201,5 \\
\hline 54 & Guadalupe & 16,9 & 20,7 & 51,8 & 125,3 & 189,1 \\
\hline 55 & Cingapura & 9,2 & 20,4 & 48,3 & 211,5 & 252,5 \\
\hline 56 & Singapura & 9,2 & 20,4 & 48,3 & 211,5 & 252,5 \\
\hline 57 & Argentina & 23,1 & 39 & 48,1 & 74,6 & 118,5 \\
\hline 58 & Antilhas Holandesas & 24,9 & 26 & 47,1 & 117,1 & 154,5 \\
\hline 59 & Istael & 19,8 & 35,9 & 46,5 & 86,9 & 131,5 \\
\hline 60 & Macau & 16,8 & 28,7 & 43,9 & 229,3 & 307,6 \\
\hline 61 & Cazaquistão & 29,7 & 24,7 & 41,4 & 81,5 & 143,4 \\
\hline 62 & China & 22,3 & 17,6 & 40,7 & 106,5 & 183,3 \\
\hline 63 & Trinidad- Tobago & 15,2 & 20 & 38,3 & 107,3 & 203 \\
\hline 64 & Azerbaijão & 34,3 & 19,7 & 36,2 & 105,1 & 212,4 \\
\hline 65 & Chile & 18,7 & 21,4 & 35,8 & 82,2 & 119,1 \\
\hline 66 & Sri Lanka & 18,3 & 17,2 & 35,3 & 90,2 & 159,5 \\
\hline 67 & Reunião & 15,3 & 14,6 & 35,2 & 85,3 & 152,5 \\
\hline 68 & Maurício & 10,4 & 11,4 & 35 & 94,7 & 149,8 \\
\hline 69 & Jamaica & 16,1 & 18,8 & 30,6 & 62,9 & 123,8 \\
\hline
\end{tabular}




\begin{tabular}{|c|c|c|c|c|c|c|}
\hline Posição & País & 1950 & 1975 & 2000 & 2025 & 2050 \\
\hline 70 & Tailândia & 12 & 11,7 & 30,5 & 87,3 & 158,1 \\
\hline 71 & Albânia & 25,9 & 17,2 & 30 & 21,9 & 19 \\
\hline 72 & Tunísia & 20,7 & 13,3 & 28,4 & 58,8 & 125,6 \\
\hline 73 & Turquia & 15,5 & 17,1 & 28,1 & 63 & 117,9 \\
\hline 74 & Líbano & 30,4 & 18,3 & 27,4 & 63,4 & 145,2 \\
\hline 75 & Nova Caledônia & 16,7 & 15,5 & 27,4 & 69,5 & 115,8 \\
\hline 76 & Brasil & 11,7 & 14,9 & 27,1 & 68,3 & 118,7 \\
\hline 77 & Bahamas & 16,9 & 14,2 & 27 & 69,6 & 118,3 \\
\hline 78 & Suriname & 20,9 & 12,2 & 26,6 & 70,3 & 178,2 \\
\hline 79 & Quirguistão & 43,1 & 21,2 & 26,5 & 53,6 & 111,4 \\
\hline 80 & Panamá & 16,1 & 15,2 & 25,9 & 68,8 & 127,6 \\
\hline 81 & Indonésia & 15,9 & 13 & 24,7 & 55,8 & 112,1 \\
\hline 82 & Santa Lúcia & 14,8 & 16 & 24,3 & 51,6 & 111,4 \\
\hline 83 & Guam & 8 & 10,2 & 24 & 51,1 & 72,6 \\
\hline 84 & Costa Rica & 13,2 & 12,4 & 23 & 59,9 & 110,5 \\
\hline 85 & Índia & 14,4 & 15,6 & 22,7 & 53,6 & 105 \\
\hline 86 & Guiana & 16,2 & 12,5 & 22,6 & 67,7 & 179,8 \\
\hline 87 & Vietnã & 22,1 & 17,4 & 22,4 & 52,8 & 118,7 \\
\hline 88 & Polinésia Francesa & 9,8 & 11,5 & 22,1 & 64,8 & 117,4 \\
\hline 89 & Peru & 13,7 & 12,9 & 21,7 & 53,4 & 113,1 \\
\hline 90 & Gabão & 37,5 & 28,9 & 21,6 & 19,3 & 36,4 \\
\hline 91 & Colômbia & 11,7 & 12,9 & 21 & 55,4 & 105,9 \\
\hline 92 & Saara Ocidental & 11,1 & 8,6 & 21 & 27,8 & 72,3 \\
\hline 93 & México & 16,9 & 12,2 & 20,9 & 58,2 & 126,2 \\
\hline 94 & Equador & 20,6 & 14 & 20,5 & 53,1 & 109,7 \\
\hline 95 & Mianmar & 14,5 & 15,7 & 20,5 & 52,6 & 109,7 \\
\hline 96 & El Salvador & 11,1 & 10,4 & 20,2 & 41,4 & 99,8 \\
\hline 97 & Emirados Árabes Unidos & 13,4 & 12,2 & 19,7 & 120,9 & 143,7 \\
\hline 98 & República Dominicana & 11,6 & 10,4 & 19,7 & 50,2 & 98,7 \\
\hline 99 & Uzbequistão & 28,8 & 17,9 & 19,5 & 47,9 & 112 \\
\hline 100 & Venezuela & 7,9 & 11,4 & 19,4 & 54,6 & 105,5 \\
\hline 101 & Malásia & 17,9 & 13,3 & 19,3 & 56,7 & 104,9 \\
\hline 102 & Marrocos & 10,3 & 11 & 18,4 & 47,1 & 102,4 \\
\hline 103 & Guiana Francesa & 28,7 & 18,3 & 18,4 & 37,6 & 59,6 \\
\hline 104 & Egito & 13 & 16,2 & 17,8 & 47,5 & 103,5 \\
\hline 105 & Argélia & 17 & 12,8 & 17,4 & 47,3 & 113 \\
\hline
\end{tabular}




\begin{tabular}{|c|c|c|c|c|c|c|}
\hline Posição & País & 1950 & 1975 & 2000 & 2025 & 2050 \\
\hline 106 & Tadjiquistão & 22,1 & 14,8 & 17,3 & 40,3 & 104,9 \\
\hline 107 & Turcomenistão & 29 & 15,6 & 17,2 & 44,1 & 99,3 \\
\hline 108 & Fiji & 9,6 & 11,2 & 17,1 & 55,9 & 130,8 \\
\hline 109 & Bahrein & 10,9 & 8,3 & 16,7 & 100,5 & 137,2 \\
\hline 110 & África do Sul & 15,4 & 12,1 & 16,7 & 38,8 & 58,1 \\
\hline 111 & Lesoto & 17 & 14,2 & 16,7 & 22,9 & 38,6 \\
\hline 112 & Cabo Verde & 19,1 & 17,4 & 16,6 & 32,6 & 94,9 \\
\hline 113 & Samoa & 8,4 & 7 & 16,5 & 19 & 64,7 \\
\hline 114 & Líbia & 17,3 & 8,1 & 16,2 & 41,2 & 105 \\
\hline 115 & Brunei & 20,8 & 14 & 16,1 & 80,5 & 126,4 \\
\hline 116 & Mongólia & 13,1 & 10,8 & 15,8 & 44,9 & 117,6 \\
\hline 117 & Belize & 15,5 & 14,5 & 15,7 & 41,9 & 109,8 \\
\hline 118 & Bolívia & 13,6 & 12,9 & 15,5 & 30,7 & 74,9 \\
\hline 119 & Butão & 14,5 & 13,9 & 15,2 & 19,6 & 50,3 \\
\hline 120 & Filipinas & 12,7 & 11,2 & 14,8 & 41,7 & 95,9 \\
\hline 121 & Nepal & 15,9 & 139 & 14,4 & 21,4 & 52,7 \\
\hline 122 & Rep.Centro-Africana & 21,2 & 15,7 & 14,2 & 15,8 & 36,4 \\
\hline 123 & Kuwait & 12,4 & 5,9 & 14,1 & 68,6 & 130,4 \\
\hline 124 & Irã & 21,1 & 12 & 14 & 41,8 & 107,8 \\
\hline 125 & Haiti & 22,3 & 17 & 13,9 & 23,9 & 68 \\
\hline 126 & Paquistão & 21,7 & 13,1 & 13,8 & 21,1 & 53,8 \\
\hline 127 & Sudão & 12,2 & 10,2 & 13,6 & 25,6 & 63,5 \\
\hline 128 & Guiné Equatorial & 25,9 & 16,9 & 13,6 & 14,2 & 31,7 \\
\hline 129 & Paraguai & 22,9 & 16,5 & 13,5 & 30,6 & 72,1 \\
\hline 130 & Laos & 11 & 10,8 & 13,1 & 21,5 & 57,4 \\
\hline 131 & Camarões & 14,4 & 13,2 & 13 & 16,9 & 45,2 \\
\hline 132 & Guiné Bissau & 15,9 & 14,7 & 13 & 13,3 & 28,1 \\
\hline 133 & Gâmbia & 13,3 & 11,5 & 12,9 & 23,5 & 51 \\
\hline 134 & Namíbia & 14,7 & 12,8 & 12,9 & 16,4 & 44,9 \\
\hline 135 & Bangladesh & 16,4 & 12,2 & 12,8 & 29,8 & 72,9 \\
\hline 136 & Suazilândia & 10,6 & 10,3 & 12,8 & 17,1 & 35,4 \\
\hline 137 & Djibuti & 7,4 & 7,9 & 12,8 & 15,3 & 20,6 \\
\hline 138 & Mali & 9,2 & 9,2 & 12,5 & 11,8 & 21 \\
\hline 139 & Gana & 9,1 & 9,7 & 12,4 & 23,5 & 63,2 \\
\hline 140 & Honduras & 8,7 & 8,6 & 12,2 & 27,9 & 74,6 \\
\hline 141 & Guatemala & 9,7 & 9,7 & 12,1 & 21,6 & 63,9 \\
\hline
\end{tabular}




\begin{tabular}{|c|c|c|c|c|c|c|}
\hline Posição & País & 1950 & 1975 & 2000 & 2025 & 2050 \\
\hline 142 & Maldivas & 24,8 & 16,4 & 12,1 & 16,9 & 50 \\
\hline 143 & Vanuatu & 9,3 & 9,7 & 11,8 & 23,2 & 61,1 \\
\hline 144 & Costa do Marfim & 9,3 & 8,9 & 11,8 & 19,4 & 50,9 \\
\hline 145 & Catar & 13,4 & 9,2 & 11,7 & 102,8 & 104,7 \\
\hline 146 & Moçambique & 11,3 & 11,8 & 11,6 & 12,8 & 29,2 \\
\hline 147 & Síria & 16,4 & 10,8 & 11,5 & 26,9 & 82,7 \\
\hline 148 & Jordânia & 16,3 & 9,2 & 11,4 & 22,8 & 69,1 \\
\hline 149 & Arábia Saudita & 13,3 & 10,9 & 11,2 & 22,4 & 55,8 \\
\hline 150 & Timor Leste & 13,8 & 10,7 & 11 & 32,9 & 82,6 \\
\hline 151 & Iraque & 9,5 & 8,7 & 11 & 24 & 67 \\
\hline 152 & Togo & 16,4 & 10,8 & 11 & 14,9 & 40 \\
\hline 153 & Congo & 14,2 & 12,4 & 11 & 10,8 & 22,3 \\
\hline 154 & Afeganistão & 10,6 & 10,8 & 10,9 & 12,9 & 25,4 \\
\hline 155 & Botsuana & 13,3 & 6,6 & 10,8 & 18,9 & 48,5 \\
\hline 156 & Serra Leoa & 13,3 & 12,4 & 10,8 & 11,2 & 22 \\
\hline 157 & Nicarágua & 9,3 & 8,3 & 10,7 & 25,6 & 72,9 \\
\hline 158 & Eritreia & 11,3 & 9,4 & 10,7 & 16,1 & 39,6 \\
\hline 159 & Mauritânia & 11,2 & 11,5 & 10,7 & 13,6 & 32,7 \\
\hline 160 & Nigéria & 12,3 & 10,7 & 10,6 & 15,2 & 41,2 \\
\hline 161 & Territ. Ocupação Palestina & 16,3 & 10,7 & 10,6 & 14,4 & 37,2 \\
\hline 162 & Madagascar & 11,2 & 10,9 & 10,6 & 14,6 & 34,9 \\
\hline 163 & Libéria & 12,1 & 12,5 & 10,6 & 7 & 20 \\
\hline 164 & Chade & 18,2 & 13,1 & 10,5 & 10 & 22,1 \\
\hline 165 & Etiópia & 10,9 & 9,8 & 10,5 & 11,8 & 20,4 \\
\hline 166 & Zimbábue & 12,8 & 9,8 & 10,4 & 15,3 & 45,6 \\
\hline 167 & Papua - Nova Guiné & 15,3 & 8,5 & 10,3 & 19,7 & 52,2 \\
\hline 168 & Guiné & 9,9 & 9,9 & 10,1 & 14,4 & 36,5 \\
\hline 169 & Malauí & 10,8 & 7,8 & 10 & 10,8 & 20,4 \\
\hline 170 & Camboja & 10,8 & 11 & 9,9 & 19,5 & 48,2 \\
\hline 171 & Burquina Fasso & 10,8 & 10,5 & 9,9 & 8,1 & 19,2 \\
\hline 172 & Comores & 12,3 & 9,1 & 9,8 & 16 & 51,1 \\
\hline 173 & Zâmbia & 9,7 & 8,9 & 9,8 & 9,8 & 27,5 \\
\hline 174 & Quênia & 15,9 & 9,8 & 9,6 & 18,2 & 53,4 \\
\hline 175 & Omã & 11,7 & 10 & 9,6 & 16,9 & 39,1 \\
\hline 176 & Senegal & 132 & 10,5 & 9,5 & 15,5 & 45 \\
\hline 177 & Ruanda & 8,4 & 8,3 & 9,5 & 11 & 32,9 \\
\hline
\end{tabular}




\begin{tabular}{llccccc}
\hline Posição & País & 1950 & 1975 & 2000 & 2025 & 2050 \\
\hline 178 & Ilhas Salomão & 7,6 & 10,2 & 9,4 & 14,4 & 43,8 \\
179 & Angola & 11,9 & 11,2 & 9,4 & 8,3 & 14,1 \\
180 & Rep.Dem. do Congo & 12,8 & 10,1 & 9,3 & 9 & 19,6 \\
181 & Benin & 37,6 & 12,2 & 9,1 & 13,3 & 32,8 \\
182 & Burundi & 12,7 & 12,1 & 9,1 & 10,1 & 20,3 \\
183 & Tanzânia & 8,2 & 7,9 & 8,9 & 14,6 & 45,4 \\
184 & Somália & 11,2 & 10,5 & 8,1 & 8,7 & 15,7 \\
185 & Uganda & 10,8 & 8,7 & 7,7 & 7,2 & 16,3 \\
186 & Lêmen & 14,7 & 8,6 & 7,3 & 7,8 & 14,3 \\
187 & Niger & 9,1 & 7,9 & 6,6 & 7,3 & 13,1 \\
\hline
\end{tabular}

Fonte: Elaborada pelas autoras com base nas informações sobre o Índice de Envelhecimento disponibilizadas pelas Nações Unidas - Population Division, DES A: World Population Ageing 1950-2050. ${ }^{17}$

$\mathrm{Na}$ análise das principais regiões, observouse que 27 países apresentavam, em 2000, um número maior de idosos do que jovens com idade entre 0 e 15 anos (tabela 2), sendo apenas um deles localizado na Ásia e os demais na Europa.

Os cinco países com população mais envelhecida, em 2000, eram Itália, Japão, Grécia, Alemanha e Espanha, sendo quatro europeus e um asiático e todos considerados nações desenvolvidas. Por outro lado, os cinco países com população mais jovem eram Niger, Lêmen, Uganda, Somália e Tanzânia, sendo quatro deles localizados na África e um na Ásia e considerados menos desenvolvidos. ${ }^{17}$

Observou-se que 27 países possuíam pelo menos um idoso para cada menor de 15 anos, sendo 18 destes países (66\%) considerados desenvolvidos. ${ }^{17,21}$

Nas diferentes regiões do planeta, em 2000, os países com a população mais envelhecida em cada continente eram: Ilhas Reunião, na África; Canadá, nas Américas; Japão, na Ásia; Itália, na Europa; e Austrália, na Oceania. $\mathrm{Na}$ América do Sul, o Uruguai mostrou-se o país mais envelhecido e o Paraguai o mais jovem. Já na América Central e Caribe, Martinica era o país com o maior IE e a Nicarágua o país com o menor IE. ${ }^{17}$
Em 2000, as regiões mais desenvolvidas registraram um IE de 106,2, comparado ao número de 23,4, apresentado nas regiões menos desenvolvidas. ${ }^{17} \mathrm{Na}$ projeção para 2050 , os cinco países que deverão ter os maiores IEs serão Espanha, Itália, Áustria, Eslovênia e Japão (sendo que $60 \%$ já mostravam este comportamento em 2000) e os cinco países mais jovens serão Niger, Angola, Lêmen, Somália e Uganda (80\% mostravam este comportamento). ${ }^{17}$

Todos os países considerados desenvolvidos atualmente terão pelo menos um idoso para cada jovem, 37 países terão entre 2 e 2,99 idosos por cada jovem e dez países terão 3 ou mais idosos para cada jovem, sete deles na Europa e três na Ásia. ${ }^{17,21}$ Por outro lado, o IE deverá manter-se menor que 25 em 17 países ou áreas, principalmente na África, ou seja, haverá mais de quatro crianças por cada idoso. ${ }^{17}$

Como observado, IEs são normalmente menores em países em desenvolvimento do que no mundo desenvolvido, mas, no futuro, este padrão deverá se alterar e se as taxas de fecundidade se mantiverem relativamente altas no futuro, a variação absoluta do IE será pequena. ${ }^{19}$ Esperase que o aumento proporcional no IE nos países em desenvolvimento seja maior do que em países desenvolvidos. ${ }^{22}$ As projeções sinalizam um 
crescimento de $278,63 \%$ para as regiões menos desenvolvidas - maior, portanto, que o previsto para as desenvolvidas, de $102,78 \%{ }^{17}$

Muitas variáveis precisam ser consideradas quando analisamos o fenômeno do envelhecimento populacional, entre elas, as taxas de fecundidade, as taxas de mortalidade, a migração, e também outras, mais subjetivas, de difícil mensuração, como as políticas públicas, o modo de vida, a cultura, as mudanças de pensamento e de comportamento. As diferenças encontradas entre estas variáveis é que fazem com que o processo do envelhecimento aconteça de forma diferente entre os países, dentro de um mesmo país e, até mesmo, entre locais e regiões. ${ }^{23}$

Entretanto, é importante considerar algumas limitações do índice, relacionadas às imprecisões da base de dados utilizada para o cálculo do indicador, as falhas na declaração da idade nos levantamentos estatísticos ou à metodologia empregada para elaborar estimativas e projeções populacionais. ${ }^{12}$ As fontes de dados normalmente utilizadas para o cálculo do IE são o IBGE, por meio do Censo Demográfico, Contagem da População, Pesquisa Nacional por Amostra de Domicílios (PNAD), estimativas e projeções demográficas e da matriz de indicadores básicos. ${ }^{12}$

A profunda, abrangente e duradoura mudança na estrutura etária da população pode oferecer boas oportunidades para todos, mas também impõe enormes desafios, requerendo especial atenção na formulação de políticas sociais, destinadas a garantir as condições mínimas de bem-estar ao crescente grupo de idosos. ${ }^{17,24}$

\section{REFERÊNCIAS}

1. Instituto Brasileiro de Geografia e Estatística(IBGE). Diretoria de Pesquisas. Coordenação de População e Indicadores Sociais. Estudos e Pesquisas. Informação Demográfica e Socioeconômica. Síntese de Indicadores Sociais. Rio de Janeiro: IBGE; 2001-2010 [acesso em 4 mai 2011]; Disponível em: http://www.ibge.gov.br/

2. Nasri F. O envelhecimento populacional no Brasil. Einstein. 2008;6 (Supl 1):S4-S6.

\section{CONCLUSÃO}

As condições de saúde de determinada população podem ser estimadas por meio de indicadores demográficos. O conhecimento de aspectos demográficos permite avaliar, além das necessidades, as demandas presentes e futuras de recursos de toda natureza. ${ }^{25} \mathrm{O}$ conjunto de informações e indicadores gerado pelos estudos demográficos tem especial relevância para a análise das condições de vida da população, acompanhamento e apoio à decisão com relação às políticas públicas, investimentos em saúde $\mathrm{e}$ intervenções específicas em áreas críticas. ${ }^{1} \mathrm{~A}$ escolha dos indicadores depende dos objetivos da avaliação, dos aspectos metodológicos, éticos e operacionais da questão em estudo. ${ }^{25}$ O Índice de Envelhecimento (IE) permite observar a evolução do ritmo de envelhecimento da população, comparativamente entre áreas geográficas e grupos sociais.

O processo de envelhecimento populacional é uma realidade no Brasil e no mundo, representando um importante fenômeno demográfico da atualidade e que modificou a perspectiva de vida dos indivíduos. ${ }^{26}$

Uma vez que o século XXI testemunhará um envelhecimento mais rápido do que o ocorrido no século passado, ${ }^{12}$ o desafio para o futuro é garantir que os indivíduos possam envelhecer com segurança e dignidade, mantendo sua participação ativa na sociedade, como cidadãos e com todos seus direitos assegurados, sempre compatíveis com aqueles de outras faixas etárias e que as relações entre as gerações sejam constantemente estimuladas. ${ }^{17}$

3. Ramos LR, Veras RP, Kalache A. Envelhecimento populacional:uma realidade brasileira. Rev de Saude Publica. 1987;21(3):211-224.

4. Carvalho JAM, Wong LLR. A transição da estrutura etária da população brasileira na primeira metade do século XXI. Cad Saude Publica.2008 Mar;24(3):597-605.

5. IBGE. Instituto Brasileiro de Geografia e Estatística. Censos Demográficos. [acesso em 4 mai 2011]; Disponível em: http://www.ibge.gov.br. 
6. Carvalho JAM. Regional trends in fertility and mortality in Brazil. Popul Stud. 1974 Nov; 28(3): 401-421

7. Frias LAM, Carvalho JAM. Fecundidade nas regiões brasileiras a partir de 1903: Uma tentativa de reconstrução do passado através das gerações. In: Encontro Nacional de Estudos Populacionais; 1994; Belo Horizonte: Associação Brasileira de Estudos Populacionais;1994. p.23-46.

8. Carvalho JAM, Garcia RA. O envelhecimento da população brasileira: um enfoque demográfico. Cad Saude Publica. 2003 Mai-Jun;19(3):725-733.

9. Moreira MM. Mudanças estruturais na distribuição etária Brasileira: 1950-050. 2002 Mai; Trabalhos para Discussão n. 117.

10. Alves, JED. Transição da fecundidade e relações de gênero no Brasil. Tese [Doutorado em Economia]. Belo Horizonte (MG) - Centro de Desenvolvimento e Planejamento Regional. Universidade Federal de Minas Gerais; 1994

11. United Nations. Report of the World Assembly on Aging. 1982 Jul-Aug; Vienna, Austria: New York: United Nations; 1982.

12. Rede Internacional de Informações para a saúde(RIPSA). Departamento de Informática do SUS/Ministério da Saúde(DATASUS). Características dos indicadores - Fichas de qualificação, 2009. [acesso em 24 abr 2011]; Disponível em: http://www.ripsa.org.br/.

13. Moreira MM. Envelhecimento da População Brasileira.Tese[Doutorado] Belo Horizonte (MG): Centro de Desenvolvimento e Planejamento Regional da Universidade Federal de Minas Gerais; 1997.

14. United Nations. Report of the Second World Assembly on Ageing; Building a society for all ages. Madrid, Spain; New York: United Nations; 2002 Apr: chap. I, resol. 1, annex II.

15. Brasil. Política Nacional do Idoso e criação do Conselho Nacional do Idoso e outras providências. Lei 8842. (4. Jan. 1994).

16. Brasil. Estatuto do Idoso. Lei 10741. (1. Out. 2003).
17. United Nations. DESA-Department of Economic and Social Affairs. Population Division. World Population Ageing 1950-2050. 2002. [acesso em 10 out 2010]; Disponível em: http://www.un.org/esa/ population/publications/unpop.htm.

18. Moreira MM. Envelhecimento da população brasileira em nível regional: 1995-2050. IN: ABEP. Encontro Nacional de Estudos Populacionais 11. Caxambu. Anais. Belo Horizonte, ABEP, 1998.

19. Kinsella K., He W, Way PO. An Aging World: 2008 U.S. Census Bureau,. U.S. Government Printing Office, Washington, DC; 2009. Series P95/09-1.

20. Shryock HS, Siegel JS. The Methods and Materials of Demography. Washington, DC: Bureau of Census - U.S. Government Printing Office, 1980.

21. BRASIL. Programa das Nações Unidas para o Desenvolvimento(PNUD). Ranking do Índice de Desenvolvimento Humano 2010. [acesso em 06 nov 2010]Disponível em: http://www.pnud. org.br/pobreza_desigualdade/reportagens/index. php?id01=3600\&lay=pde

22. Gavrilov LA, Heuveline P. Aging of population. In: Macmillan Reference USA . Encyclopedia of Population. New York, Paul Demeny and Geoffrey McNicoll; 2003 May. p.32-7. [acesso em 24 abr 2011 ]; Disponível em: http://longevity-science.org/ Population_Aging.htm.v

23. Peloso LA, Costa SMF. Caracterização do processo de envelhecimento da população e o município de São José dos Campos. In: XV Encontro Nacional de Estudos Populacionais - ABEP; 2006 Set; Caxambú (MG).21p.

24. Moreira MM. Envelhecimento da População Brasileira: intensidade, feminização e dependência. Rev Bras Estud Popul, 1998 Jan-Jun;15(1): p.79-93.

25. Pereira MG. Epidemiologia - Teoria e Prática. R. Janeiro: Guanabara Koogan AS; 2002.

26. Camarano AA. Envelhecimento da população brasileira: uma contribuição demográfica. Rio de Janeiro: IPEA; Jan 2002. Texto para discussão n ${ }^{\circ}$ 858. (26) 